\title{
Ultra Violet (UV) Sensor based on Oxide Ceramic Materials
}

\author{
Hak Ki Yu ${ }^{\dagger}$ \\ Dept. of Materials Science \& Engineering, Ajou University, \\ Suwon 16499, Korea \\ 산화물 세라믹 재료 기반 자외선 센서 \\ 류학기 $\left.\right|^{\dagger}$ \\ 아주대학교 신소재공학과 \\ (Received February 17, 2019; Accepted March 5, 2019)
}

\begin{abstract}
s
Research on ultraviolet (UV) light detection has attracted considerable attention from scientific researchers in related fields. It can be said that it is a very important time to accurately monitor the UV irradiation amount according to the wavelength region in real time. The oxide is very diverse in its kind and has the advantage of being able to efficiently control the band gap through band gap engineering. In addition, it is very stable in response to heat and atmospheric oxygen when UV is absorbed. Also, there is a known method that can effectively manufacture oxide nanoparticles and nanorods through various synthesis methods, and researches for improving the sensitivity of UV sensors have been carried out using this method. In this paper, we introduce the materials that can be used as UV sensors among various wide band oxide materials, and review the results of researches of various UV sensors using nano materials.
\end{abstract}

Keywords: UV-sensor, metal oxide, nano-materials

\section{1. 서론}

자외선 방사는 인류의 생존과 발전에 커다란 영향을 미 치기 때문에, 그 존재가 발견이 된 이래로 기존 태양 복사 의 가장 중요한 구성 요소 중 하나로 간주 되어왔다. 적당
한 시간의 자외선 피부 노출은 비타민 $\mathrm{D}$ 의 합성을 촉진 하고 구루병을 치료하거나 예방하는 등 건강에 도움을 주 지만, 과도한 자외선은 백내장 및 피부암 과 같은 다양한 질병을 유발할 수 있으며, 노화를 촉진하기도 한다. 또한 작물의 생산량과 건축물의 수명 또한 UV 복사에 의해 크 
CERAMIST

특 집 무뮤학기

게 영향을 받는 것으로 알려져 있다. 대부분의 자외선은 성층권의 오존에 의해 흡수 될 수 있기 때문에 실질적인 오존 모니터링은 1980 년대 초반이 되어서야 수행되어왔 다. 최근에는 인류에 의해 인위적으로 유발된 성층권 오 존 감소로(남극 성층권의 오존 파괴) 인하여 지표에 도달 하는 자외선 복사가 증가되는 문제점이 심각하게 나타나 고 있는 실정이다.

최근 조사에 따르면 오존층의 부피가 $1 \%$ 감소하면 지 표면에서 자외선이 $2 \%$ 증가하여 피부암 발생률이 $3 \%$ 증가한다는 보고가 있다. 이러한 이유로, 자외선 광 검출 에 관한 연구는 관련 분야의 과학 연구자들로부터 상당한 주목을 끌고 있다. 이와 관련하여, 자외선은 크게 파장에 의해 $320 \sim 400 \mathrm{~nm}$ 의 파장 범위를 갖는 UV-A 밴드, $280 \sim 320 \mathrm{~nm}$ 의 파장 범위를 갖는 UV-B 밴드, 100$280 \mathrm{~nm}$ 파장 범위의 UV-C 밴드 이렇게 3가지 영역으 로 구분할 수 있다. 그 가운데 잠재적으로 인체에 미치는 영향이 가장 큰 밴드는 UV-A, UV-B 영역이며, 국제 비 이온화 방사 보호 위원회(International Commission of Non-Ionizing Radiation Protection: ICNIRP)에서는 인간에 대한 자외선 노출 한도를 규정하고 있다. ${ }^{1)}$ 따라서 파장의 영역에 따른 UV 조사량을 실시간으로 정확하게
모니터링 하는 일은 매우 중요한 시기에 도달했다고 할 수 있다.

$\mathrm{UV}$ 센서에서 가장 중요한 부분은 UV를 광학적으로 감 지하는 활성 층의 재료 선택에 있다고 할 수 있다. 첫째 로, $\mathrm{Si}$ 과 같은 밴드갭이 $(1.14 \mathrm{eV})$ 매우 작은 재료를 이용 하여 광흡수를 용이하게 하며, UV-A 혹은 UV-B와 같 은 영역의 선별을 위하여 반도체 표면에 $\mathrm{Ag}$ 와 같은 금속 막을 코팅하여 특정 자외선 파장영역 이외의 빛은 반사시 키는 방법이있다. ${ }^{2)}$ 이러한 방법은 기존의 반도체 공정을 사용할 수 있는 장점이 있지만, 대기 노출에 따른 금속 막 코팅재료의 열화(산화 및 열적 파괴)및 UV-선택 파장의 제한 등의 문제가 있다. 궁극적으로 선택적 UV 파장에 민감하게 반응하는 센서를 제작하기 위해서는, widegap $>3.1 \mathrm{eV},<400 \mathrm{~nm}$ ) 반도체를 활용하는 방법이 필 요하다. 이러한 접근의 경우 두 가지 사안을 고려해야 하 는데, 첫째는 UV-A 혹은 UV-B를 분해할 수 있는 센서 의 선택도 이다. 이 경우에는 wide-gap 반도체의 합금 화를 통해 band-gap engineering을 이용하여 해결할 수 있다. 둘째는 센서의 민감도인데, wide-gap의 경우 도핑을 통한 전하 농도의 증가를 유도하기 어렵기 때문 에, 결함이 적은 나노 사이즈(나노 판상, 나노 막대)의 재

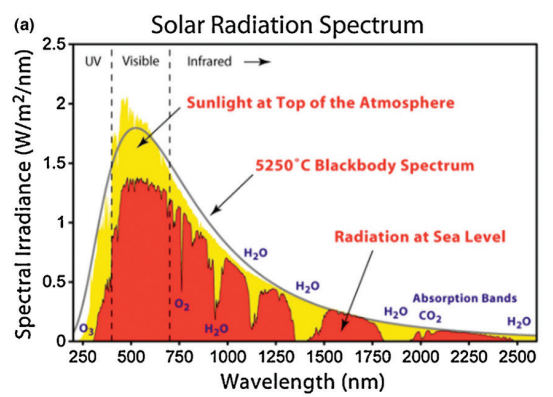

(b)
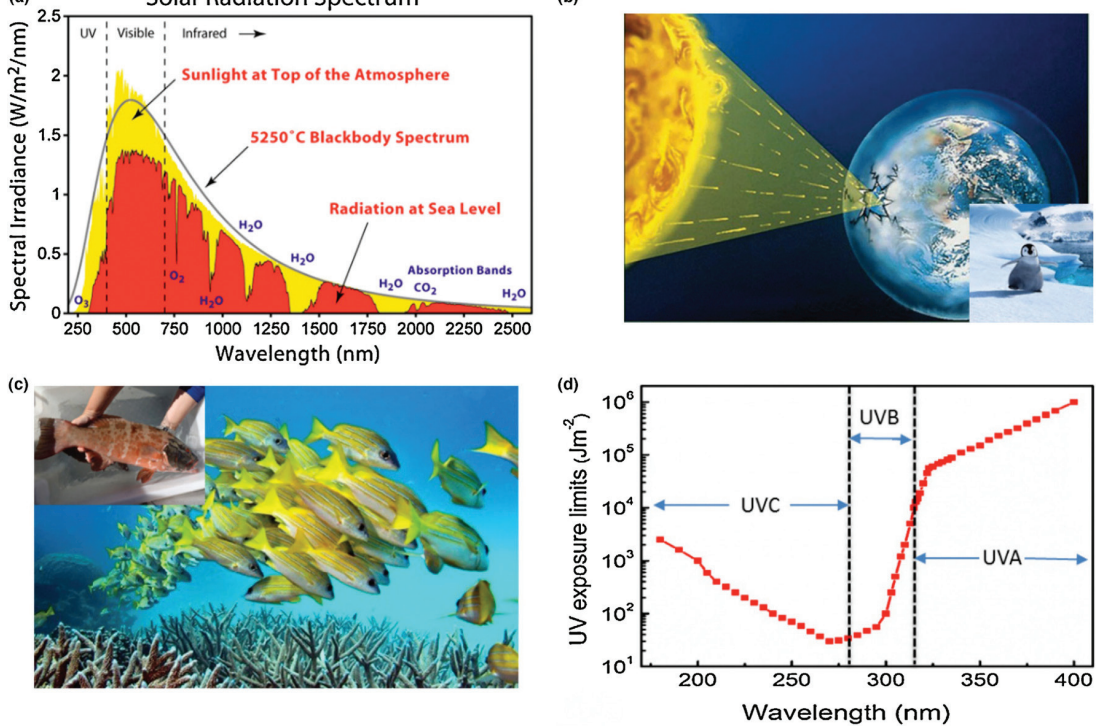

Fig. 1. (a) 태양 조사 스펙트럼. (b) 남극 대륙의 오존 구멍. (c) 딱딱한 산호초 위에서 수영하는 파란 줄무늬 물떼새의 무리. 삽 입은 피부 암이 있는 표정 버섯 표범 (plectropomus leopardus)임. (d) UV 파장에 따른 인간의 자외선 노출 한계.1) 


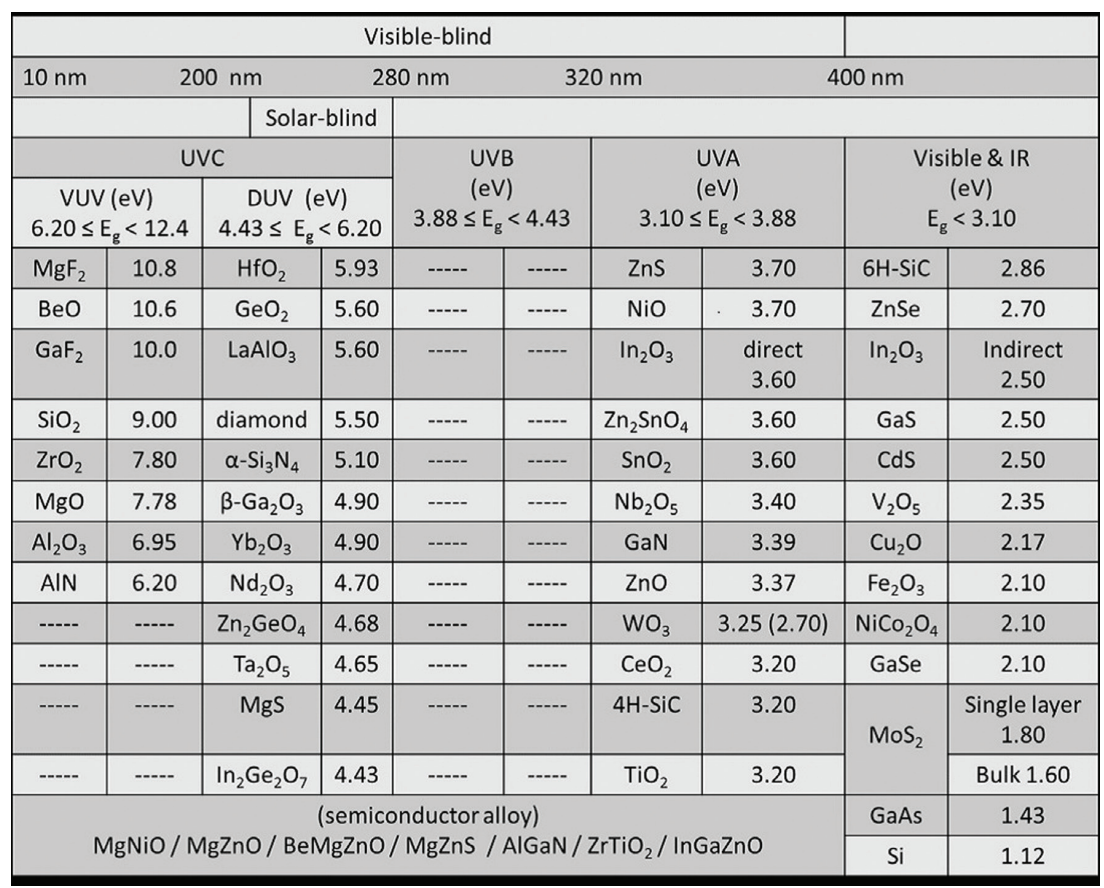

Fig. 2. 밴드 갭이 다른 UV 검출기 제조를 위한 다양한 후보 재료1)

료를 합성하여 활용하게 되면 민감도 향상을 기대할 수 있을 것이다.

현재까지 알려진 wide-gap 반도체들은 크게 탄화물 계열 $(\mathrm{SiC})$, 질화물 계열 $(\mathrm{GaN}, \mathrm{AlN})$, 그리고 산화물 계열 $\left(\mathrm{ZnO}, \mathrm{TiO}_{2}\right.$ 외 다수)로 구분할 수 있는데, 제시한 재료의 예시에서 확인할 수 있듯이 탄화물 및 질화물 계열은 재 료의 선택이 매우 제한적이다. 반면 산화물은 그 종류가 매우 다양하며, 합금화를 통해 밴드 갭의 크기를 효율적 으로 조절할 수 있는 장점도 있다. 뿐만 아니라, UV가 흡 수 될 때 발생하는 열 및 대기의 산소와의 반응에 매우 안 정적이므로 향후 UV 센서 개발에 있어 매우 다양한 연구 가치가 있을 것으로 판단된다. 또한 다양한 합성 방법으 로 통해 산화물 나노 판상 및 나노 막대 들을 효과적으로 제작할 수 있는 방법이 알려져 있어 이를 활용하여 UV 센 서의 민감도 또한 향상시키는 연구가 많이 진행되고 있 다. 본 논문에서는 다양한 wide band gap 산화물 재료 가운데 UV 센서로 활용이 가능한 재료를 소개하고 이를 활용한 다양한 나노 소재적용 UV 센서 연구 결과를 리뷰 하고자 한다.

\section{2. 산화 아연(ZnO) 기반 UV 센서}

$\mathrm{ZnO}$ 는 대표적인 wide-gap 산화물 반도체로서, 다양 한 광전소자(발광다이오드, 태양전지, 광검출기 등)로 많 이 응용되어왔다. 특히, $\mathrm{ZnO}$ 는 Wurtzite 결정구조를 가 지며, c-축 방향(0002)면으로 아연이온과 산소이온이 교차로 적층 되어 높은 극성 특성을 가진다. 이로 인해, $\mathrm{c}$-축 방향으로 성장을 조절하기 용이해 다양한 나노 구 조체를 제작할 수 있다. ${ }^{3)}$ 나노 구조체를 제작하는 방법에 있어서도 진공 증착법, 기상화학법 을 비롯하여 섭씨 100 도씨 이하의 온도의 영역에서 합성이 가능한 수열합성법 등 다양한 방법이 가능하다. 이로 인해 유연소자제작에도 널리 활용이 되고 있는 추세이다. 다만, $\mathrm{ZnO}$ 는 산과 같 은 용액에 부식이 매우 빠르기 때문에 다양한 대기 환경 에서 장시간 사용되는 UV 센서의 경우 효과적인 보호막 제작이 동반될 필요가 있다.

2011년 Advanced Functional Material에 출판된 논 문에 따르면, 수직 합성된 $\mathrm{ZnO}$ (0002)나노 막대를 일정 방향으로 눕혀 센서를 제작하게 되면 $\mathrm{ZnO}$ 의 밀도에 따 

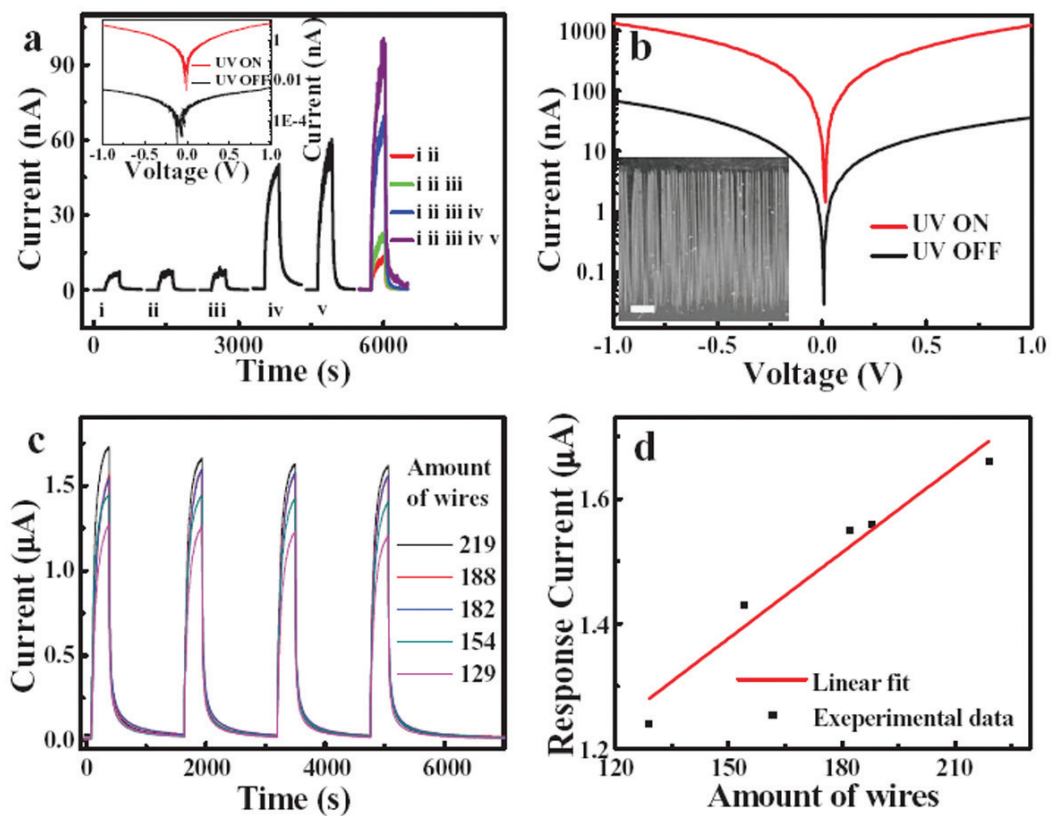

Fig. 3. (a) (d) ZnO 나노 막대의 배열을 통해 배열된 나노막대의 개수에 따른 UV 센서 민감도 측정 결과 ${ }^{4)}$

라 UV-A의 민감도를 조절할 수도 있으며 유연한 소자 제작 또한 가능함이 알려 졌다. 뿐만 아니라, 나노 구조 체를 활용하여 $100 \mathrm{nW} / \mathrm{cm}^{2}$ 의 매우 낮은 UV-A도 쉽게 검출함을 실험적으로 증명 하였다. ${ }^{4)}$

뿐만 아니라, $\mathrm{ZnO}$ 나노 막대를 합성함에 있어 UV 센 서 전극을 촉매 $(\mathrm{Au}$ 전극 흑은 그래핀 전극)로 활용하여 전극 쪽에서만 성장이 개시되어 나노 막대 사이 자발적 연결을 유도하는 방법 또한 개발되었다. ${ }^{5-7)}$ 이 경우 센서 제작을 위해 추가적인 나노 막대의 전사공정이 필요하지 않는 장점이 있다.

\section{3. $\mathrm{TiO}_{2}$ 기반 UV 센서}

$\mathrm{TiO}_{2}$ 는 대표적인 광촉매 산화물로서 exciton 결합에 너지가 낮아 UV 흡수 시 전자-정공을 효과적으로 분리 해주는 역할을 하는 재료이다. 이를 활용하여 UV-센서 (UV-A) 를 제작하는 연구가 활발히 진행되었는데, 초기 에는 박막형 UV-sensor로 연구가 진행이 되었지만,8) $\mathrm{TiO}_{2}$ 층을 얇게 활용하여 민감도를 증가시키는 방향으로 연구가 진행되고 있으며, 원자단위 증착법(ALD)을 이용
하거나, 나노 입자 코팅(나노 막대, 나노 입자) 방법을 통 해 이를 달성하고자 하고 있다. ${ }^{9-11)}$

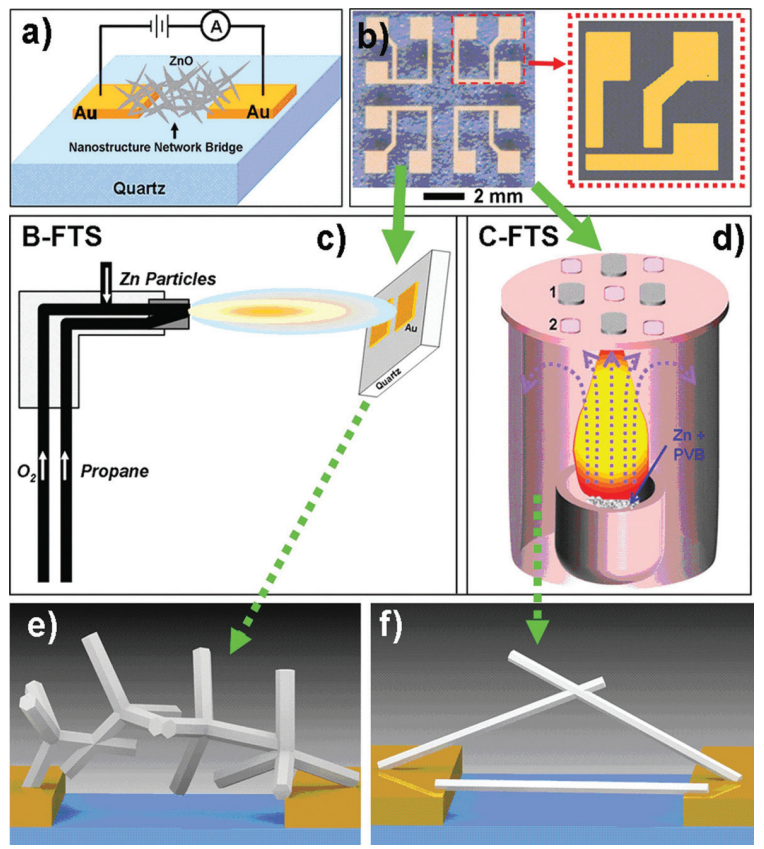

Fig. 4. (좌) $\mathrm{Au}$ (우) Graphene 전극상에 선택적으로 성장한 $\mathrm{ZnO}$ 나노 막대5-6) 

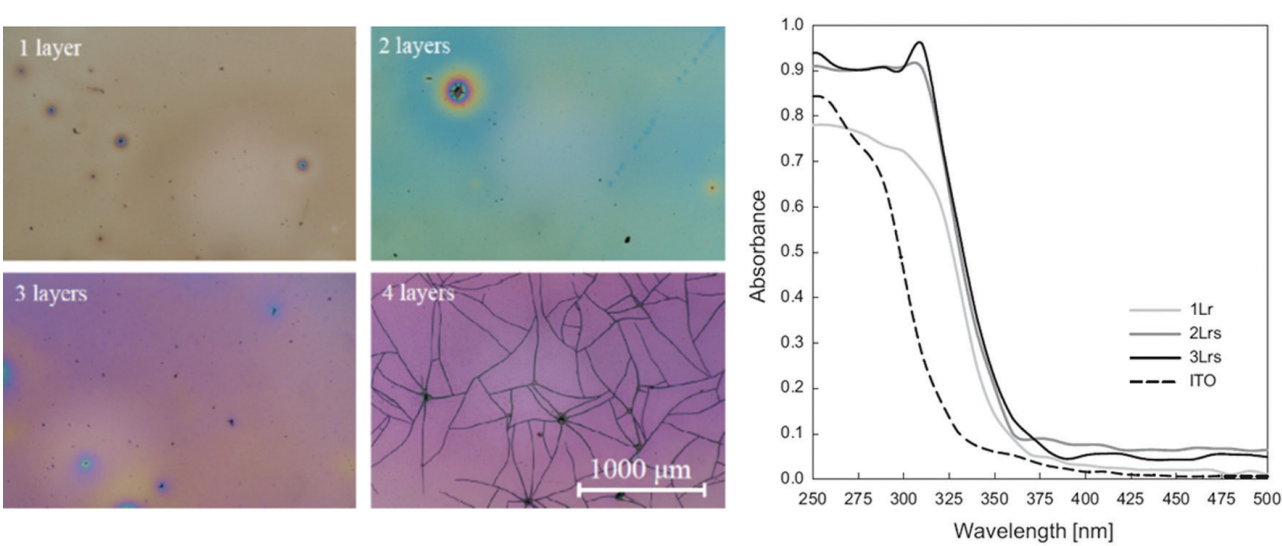

Fig. 5. sol-gel 법으로 제작된 $\mathrm{TiO}_{2}$ 박막의 (좌) 광학 사진 과 (우) UV-vis 스펙트럼8)
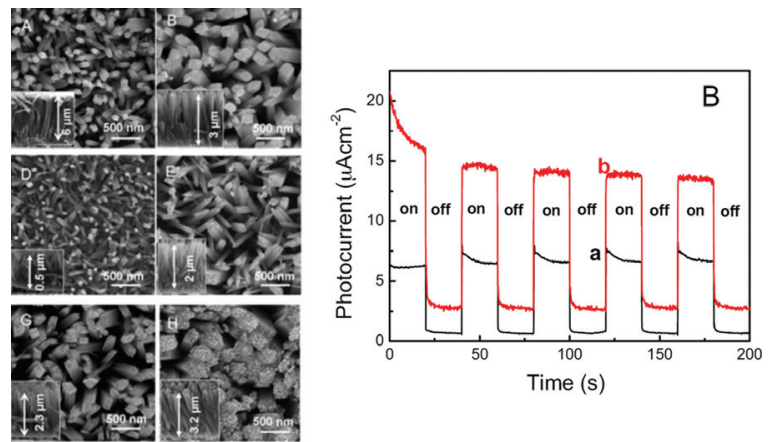

Fig. 6. 수열합성법을 이용하여 FTO 유리 기판상에 성장된 (좌) $\mathrm{TiO}_{2}$ 나노 구조체 전자현미경 사진 (우) UV-센서 측정 결과)

\section{4. $\mathrm{Nb}_{2} \mathrm{O}_{5}$ 기반 UV 센서}

앞서 언급한 $\mathrm{ZnO}, \mathrm{TiO}_{2}$ 와 같은 산화물은 주로 UV-A 와 보라색 영역 가시광선의 경계에 해당하는 band-gap 을 가지기 때문에 UV-A를 측정하는 센서로는 유용하나 보다 짧은 파장의 UV-B를 분해하는데 한계가 있다. 근 래 이러한 문제를 해결하게 위해 보다 band-gap이 큰 산화물 재료들이 실험적으로 제안 되었으며, 그 가운데 우선적으로 $\mathrm{Nb}_{2} \mathrm{O}_{5}$ 에 해당하는 연구 결과를 소개하고자 한다.

$\mathrm{Nb}_{2} \mathrm{O}_{5}$ 는 3.5 4.8 eV에 대항하는 band-gap을 가지 며, UV-A와 UV-B를 효과적으로 분해할 수 있는 이상 적인 재료이다. $\mathrm{Nb}$ 원자가 octahedral site에 위치하며, 6 개의 산소로 둘러싸인 층이 적층으로 쌓이는 monoclinic
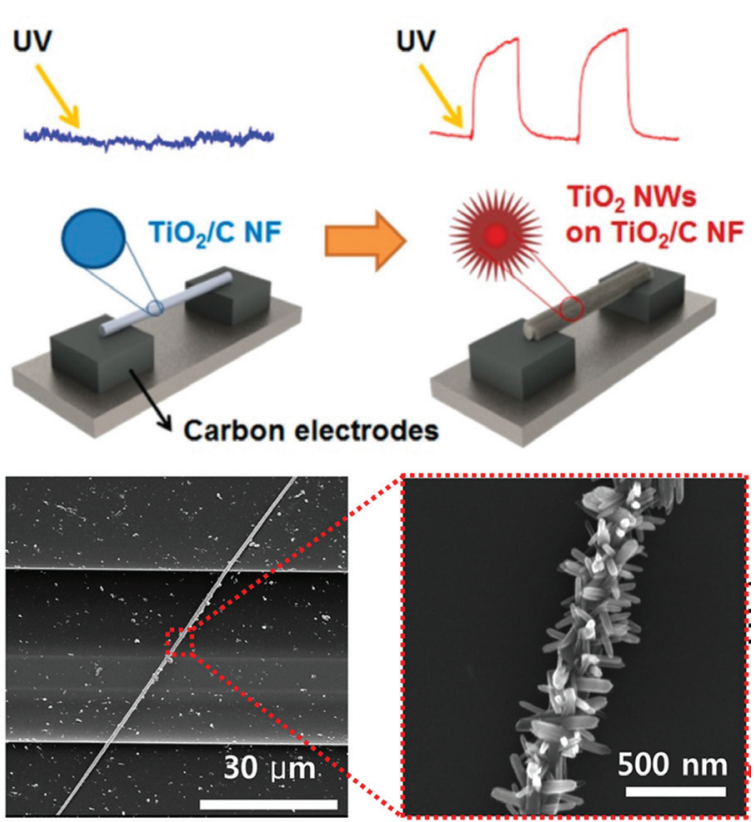

Fig. 7. $\mathrm{TiO}_{2}$ 나노 막대 가지체를 이용한 UV 센서 효율 향상10)

구조를 가진다. 2011년 $\mathrm{Nb}_{2} \mathrm{O}_{5}$ 나노 판상을 이용하여 UV 센서로의 활용을 최초로 보고하였으며, ${ }^{12)}$

비슷한 연구 결과를 $\mathrm{Nb}_{2} \mathrm{O}_{5}$ 구형 판상을 제작하여 보고 한 결과도 있다. ${ }^{13)}$ 하지만 밴드갭이 큰 산화물의 경우, 전 하의 농도가 낮은 관계로 UV 조사 시 민감도가 낮은 특 성을 보였다( pA 영역). 2018년 이를 해결하기 위해 고 밀도의 $\mathrm{Nb}_{2} \mathrm{O}_{5}$ 나노 막대를 c-plane sapphire에 증착하 여 증착과 동시에 서로 연결되어 전류의 밀도를 증가시켜 


\section{특 집 ㅁㅁ 류학기}
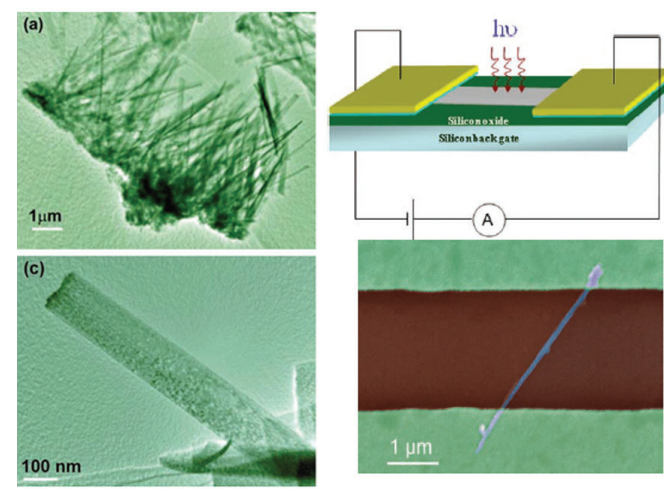

Fig. 8. $\mathrm{Nb}_{2} \mathrm{O}_{5}$ nano-beam을 이용한 UV sensor ${ }^{12)}$
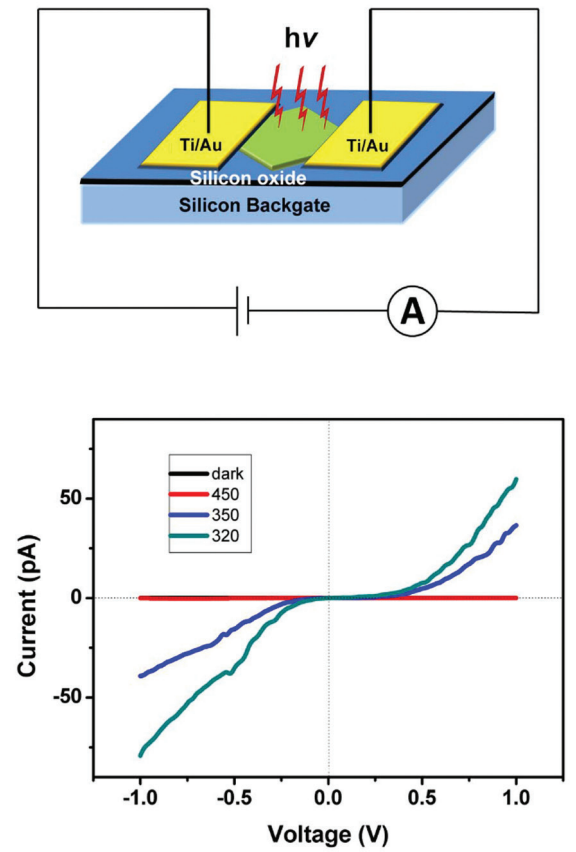

Fig. 9. $\mathrm{Nb}_{2} \mathrm{O}_{5}$ nano-plate를 이용한 UV-sensor 결과 ${ }^{13)}$

센서의 민감도를 향상( nA 영역) 시킨 연구결과도 보고 되었다. ${ }^{14}$

\section{5. $\mathrm{WO}_{3}$ 기반 UV 셴서}

$\mathrm{WO}_{3}$ 는 최근 연구되고 있는 산화물 광촉매의 대표 재 료로, $3.0 \mathrm{eV}$ 이상의 band-gap을 가지며, UV 조사 시 전기 전도도가 매우 민감하게 변하는 특성이 있어 UV 센
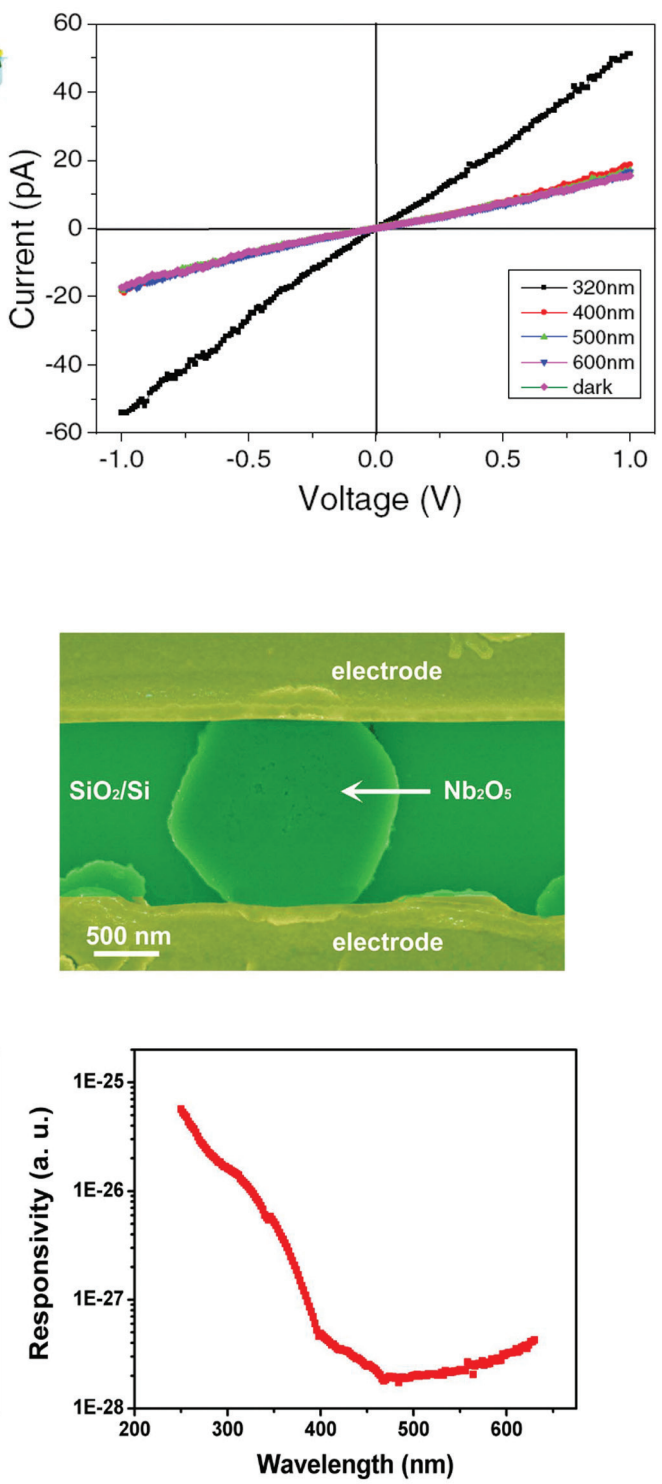

서로 연구되기 시작한 재료이다. $\mathrm{Nb}_{2} \mathrm{O}_{5}$ 와 같이 $\mathrm{W}$ 원자 주위를 6 개의 산소가 둘러싼 층상 구조가 적층되어 있는 monoclinic 구조이기 때문에, 판상으로 제작이 용이한 특성이 있다. 자체적으로 $\mathrm{n}$-형 특성을 가져 전기 전도도 가 우수하기 때문에 단일 나노 막대로 UV 조사 시 $\mathrm{nA}$ 영 역의 높은 전류흐름을 보이는 연구결과가 보고 되었다. ${ }^{15)}$

이러한 $\mathrm{WO}_{3}$ 나노 막대를 이용한 UV-sensor의 민감 도를 보다 향상시키기 위하여 Langmuir Blodgett 방법 

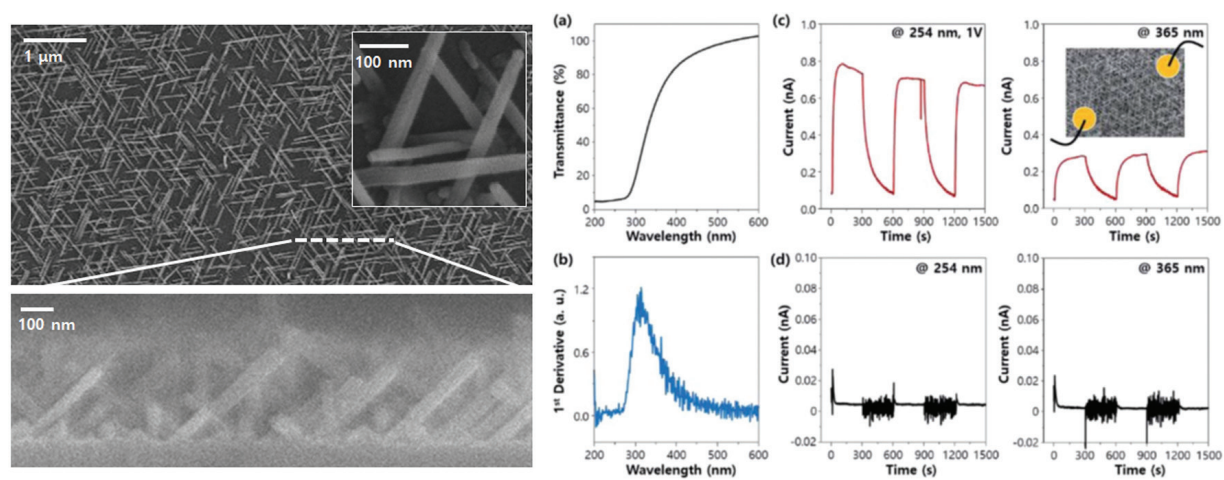

Fig. 10. Sapphire 기판에 자체 연결된 $\mathrm{Nb}_{2} \mathrm{O}_{5}$ nano-rod를 이용한 UV ( $\left.254 \mathrm{~nm} \& 365 \mathrm{~nm}\right)$ 센서 결과 4$)$
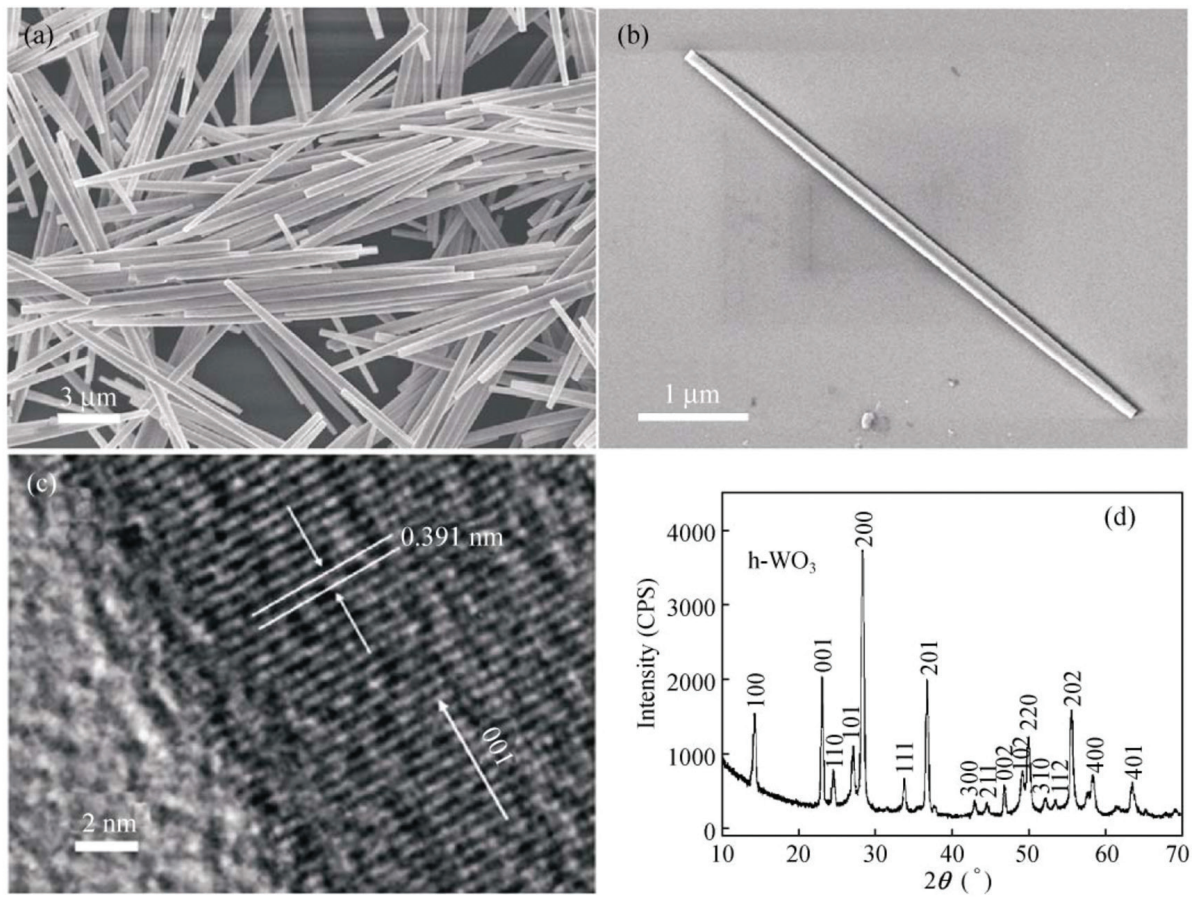

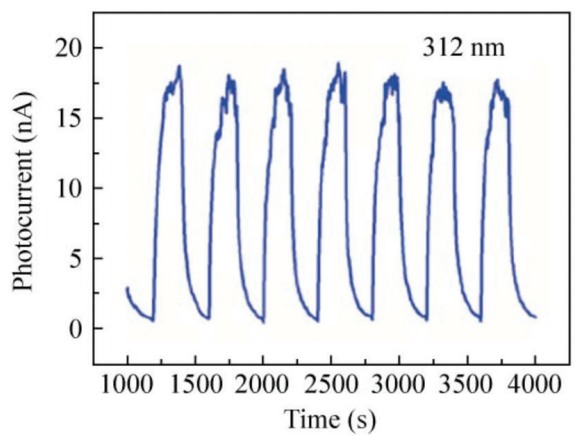

(a)

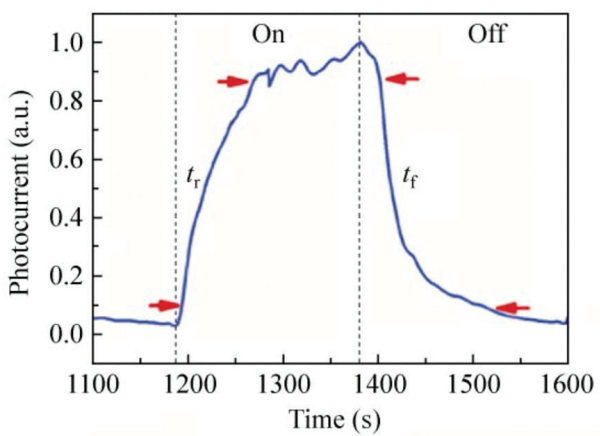

(b)

Fig. 11. $\mathrm{WO}_{3}$ 단일 나노 막대를 이용한 UV-sensor 결과(5) 


\section{특 집 ㅁㅁ류학기}
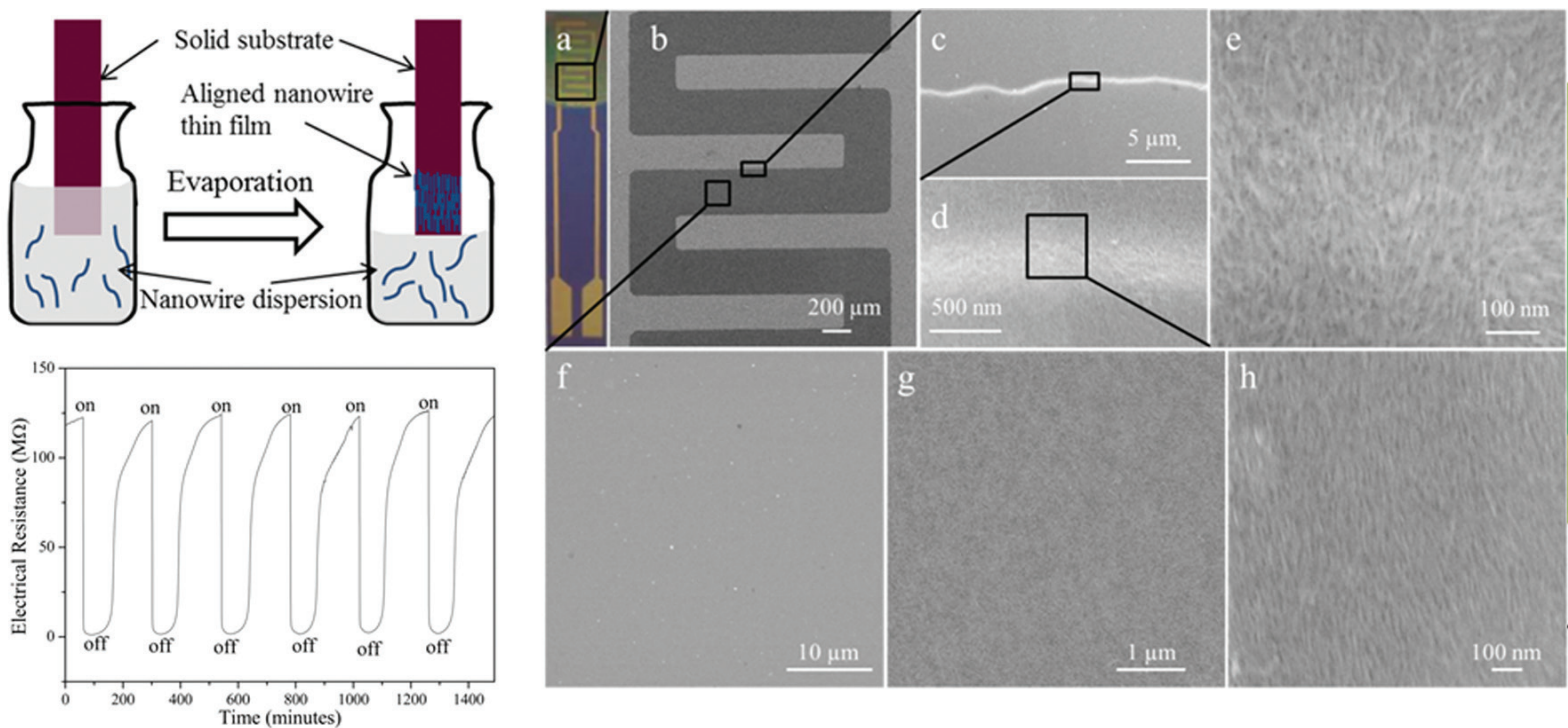

Fig. 12. Langmuir Blodgett 방법을 이용한 $\mathrm{WO}_{3}$ 나노 막대의 배열 및 밀도조절 UV-sensor 소자 ${ }^{16}$
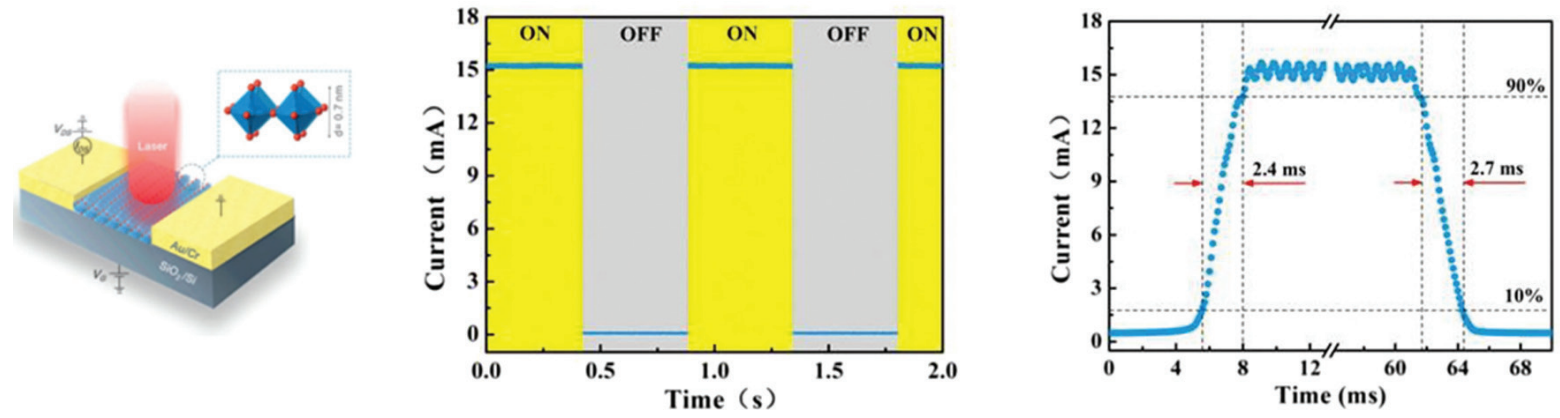

Fig. 13. $\mathrm{WO}_{3}$ 의 monoclinic 적층 구조에서 단일 층을 분리하여, 원자단위 두께의 UV-sensor ${ }^{17)}$

을 이용해(나노 막대의 배열 및 밀도조절) 소자를 제작한 결과도 최근 보고되었다. ${ }^{16)}$ 뿐만 아니라, 최근 2 차원 전 극 재료(그래핀, 전이금속칼코제나이드: TMDCs)의 개 발 연구 추세와 함께, $\mathrm{WO}_{3}$ 의 monoclinic 적층 구조에서 단일 층을 분리하여, 원자단위 두께의 UV-sensor를 제 작한 결과도 보고되었으며, 향후 유연소자 및 다양한 응 용이 기대 되고 있다. ${ }^{17)}$

\section{6. 전망과 기대}

UV을 활용하여 인류에게 이로움을 주는 다양한 과학
분야뿐만 아니라, 지구 환경 변화에 따른 급작스런 생활 $\mathrm{UV}$ 조사량 증가에 따른 생물체 보호차원에 이르기까지 UV를 탐지하는 UV 센서 기술은 매우 중요해 지고 있는 추세이다. UV 센서의 핵심기술은 조사되는 UV의 정확 한 파장 인식과(선택도), 극소량까지 측정할 수 있는 정밀 함(민감도)인데, 선택도는 다양한 금속 산화물의 합금화 를 통해 band-engineering을 통하여, 그리고 민감도는 결정성이 우수한 나노 구조체의 합성과 배열을 통하여 이 를 달성할 수 있을 것으로 기대한다. 나아가, 이러한 UV 센서의 array 기술을 개발하여, 다양한 파장별 UV 조사 량을 대량으로 분석할 수 있는 기술적 체계가 이루어 질 
필요가 있으며, IoT 기술 동향에 맞게 유연하며, 소형의 저전력형 UV-센서 소제 개발도 지속적으로 연구되어야 한다.

\section{참고문헌}

1. H. Chen, K. Liu, L. Hu, A. A. Al-Ghamdi, and X. Fang, "New concept ultraviolet photodetectors", Mater. Today, 18, 493-502 (2015).

2. W.S. Ho, C.-H. Lin, P. -S. Kuo, W. W. Hsu, and C. W. Liu, "Metal Oxide Semiconductor UV Sensor", IEEE Sensors conference, 1584-1587 (2008).

3. H. K. Yu, J. M. Baik, and J. -L. Lee, "Self-connected and habitually tilted piezoelectric nanorod array", ACS nano, 5, 8828-8833 (2011).

4. S. Bai, W. Wu, Y. Qin, N. Cui, D. J. Bayerl, and X. Wang, "High-Performance Integrated ZnO Nanowire UV Sensors on Rigid and Flexible Substrates", $A d v$. Funct. Mater., 21, 4464-4469 (2011).

5. D. Gedamu, I. Paulowicz, S. Kaps, O. Lupan, S. Wille, G. Haidarschin, Y. K. Mishra, and R. Adelung, "Rapid Fabrication Technique for Interpenetrated ZnO Nanotetrapod Networks for Fast UV Sensors", Adv. Mater., 26, 1541-1550 (2014).

6. A. Lee, J. Park, K. S. Choi, J. Lee, I. Yoo, I. S. Cho, B. Ahn, H. Seo, J. -Y. Choi, and H. K. Yu, "Position selective metal oxide nano-structures using graphene catalyst for gas sensors", Carbon, 125, 221-226 (2017).

7. A. Lee, J. -Y. Choi, and H. K. Yu, "Mimicking of Five Human Senses using Nanostructured $\mathrm{ZnO}$ Single Material", Nanotechnology, 29, 475501 (2018).

8. M. Morozova, P. Kluson, J. Krysa, P. Dzik, M. Vesely, O. Solcova, "Thin $\mathrm{TiO}_{2}$ films prepared by inkjet printing of the reverse micelles sol-gel composition", Sens. Actuators B Chem., 160, 371-378 (2011)

9. C. Cao, C. Hu, X. Wang, S. Wang, Y. Tian, H. Zhang, "UV sensor based on $\mathrm{TiO}_{2}$ nanorod arrays on FTO thin film", Sens. Actuators B Chem., 156, 114-119 (2011).

10. W. S. Lee, Y. -S. Park, andY. -K. Cho, "Hierarchically Structured Suspended $\mathrm{TiO}_{2}$ Nanofibers for Use in UV and pH Sensor Devices", ACS Appl. Mater. Interfaces, 6, 12189-12195 (2014).

11. A. M. Selman, Z. Hassan, "Highly sensitive fastresponse UV photodiode fabricated from rutileTiO 2 nanorod array on silicon substrate", Sens. Actuators A Phys., 221, 15-21 (2015).

12. X. Fang, L. Hu, K. Huo, B. Gao, L. Zhao, M. Liao, P. K. Chu, Y. Bando, and D. Golberg, "New Ultraviolet Photodetector Based on Individual $\mathrm{Nb}_{2} \mathrm{O}_{5}$ Nanobelts", Adv. Funct. Mater., 21, 3907 - 3915 (2011).

13. H. Liu, N. Gao, M. Liao, and X. Fang, "Hexagonallike $\mathrm{Nb}_{2} \mathrm{O}_{5}$ Nanoplates-Based Photodetectors and Photocatalyst with High Performances", Sci. Rep., 5, 7716 (2015).

14. K. W. Kim, B. J. Kim, S. H. Lee, T. Nasir, H. -K. Lim, I. J. Choi, B. J. Jeong, J. Lee, H. K. Yu, and J. $-\mathrm{Y}$. Choi, "Triangular radial $\mathrm{Nb}_{2} \mathrm{O}_{5}$ nanorod growth on c-plane sapphire for ultraviolet-radiation detection", RSC Advances, 8, 31066-31077 (2018).

15. K. Huang, Q. Zhang, F. Yang, and D. He, "Ultraviolet Photoconductance of a Single Hexagonal $\mathrm{WO}_{3}$ Nanowire", Nano Res., 3, 281-287 (2010).

16. W. Cheng and M. Niederberger, "EvaporationInduced Self-Assembly of Ultrathin Tungsten Oxide Nanowires over a Large Scale for Ultraviolet Photodetector", Langmuir, 32, 2474-2481 (2016).

17. Z. Hai, M. K. Akbari, C. Xue, H. Xu, S. Depuydt, S. Zhuiykov, "Photodetector with superior functional capabilities based on monolayer $\mathrm{WO}_{3}$ developed by atomic layer deposition", Sens. Actuators B Chem., 245, 954-962 (2017).

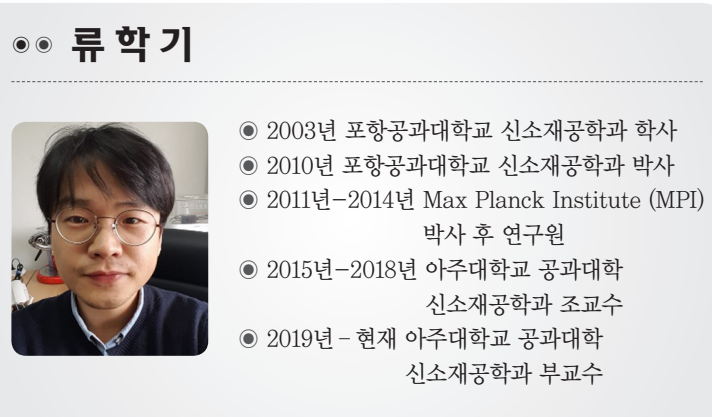

